\title{
Keefektifan Model Problem Posing Dipadu Metode Resitasi terhadap Pemahaman Konsep Siswa
}

\author{
Agung Lesmana ${ }^{1}$, Tien Aminatun ${ }^{1}$ \\ ${ }^{1}$ Pendidikan Biologi-Universitas Negeri Yogyakarta
}

\begin{tabular}{l} 
INFO ARTIKEL \\
\hline Riwayat Artikel: \\
Diterima: 23-04-2019 \\
Disetujui: 23-05-2019 \\
\hline
\end{tabular}

Kata kunci:

effectiveness; problem posing model; recitation method; conceptual understanding; keefektifan; model problem posing; metode resitasi; pemahaman konsep

\begin{abstract}
This aim of this study was to determine effectiveness of using problem posing model combined with recitation method on student's conceptual understanding. The method of this study is quasy experiment with pretest-posttest control group design, with control and experiment groups. The data analysis technique used was independent $\mathrm{t}$-test and continued with an analysis of $\mathrm{N}$-gain value to determine effectiveness. The results showed a significant difference between the posttest values of the control group and the experiment group with a significance value of $0,000(\alpha=0.05)$. The results of the analysis of $\mathrm{N}$-gain values showed that problem posing model combined with recitation method is more effective for student's conceptual understanding.
\end{abstract}

ABSTRAK

\begin{abstract}
Abstrak: Penelitian ini bertujuan untuk mengetahui keefektifan penggunaan model problem posing dipadu metode resitasi terhadap pemahaman konsep siswa. Metode penelitian ini adalah kuasi eksperimen dengan desain pretest-posttest control group design, dengan grup kontrol dan eksperimen. Tekhnik analisis data yang digunakan adalah independent t-test dan dilanjutkan dengan analisis nilai $\mathrm{N}$-gain untuk mengetahui efektivitas. Hasil penelitian menunjukkan adanya perbedaan yang signifikan antara nilai posttest grup kontrol dan eksperimen dengan nilai signifikansi $0,000(\alpha=0,05)$. Hasil analisis nilai $\mathrm{N}$-gain menunjukkan bahwa model problem posing dipadu metode resitasi lebih efektif terhadap pemahaman konsep siswa.
\end{abstract}

\author{
Alamat Korespondensi: \\ Agung Lesmana \\ Pendidikan Biologi \\ Universitas Negeri Yogyakarta \\ Jalan Colombo No.1 Kec. Depok, Kab. Sleman, Daerah Istimewa Yogyakarta \\ E-mail: agunglesmana.2017@student.uny.ac.id
}

Pendidikan merupakan landasan dan tulang punggung kemajuan suatu bangsa (Saeffudin, 2015). Karena kemajuan dan kemunduran suatu bangsa bergantung pada sumber daya manusianya (Inanna, 2018), maka pendidikan diharapkan dapat menjadi sarana dalam upaya menciptakan generasi penerus bangsa yang berkualitas. Tatanan masyarakat abad 21 menghendaki sumber daya manusia yang kuat dalam bidang sains (Sadiqin, Santoso, \& Sholahuddin, 2017) yang didalamnya termasuk juga bidang Biologi (Kurnia \& Suryadarma, 2016). Peserta didik perlu memiliki literasi sains yang memadai agar mampu hidup secara produktif untuk memperoleh kualitas hidup yang baik (ICASE, 2008). Selain itu, secara khusus peserta didik perlu menguasai Biologi agar dapat beradaptasi dengan perubahan di lingkungannya (Rustaman, 2011). Pada abad 21, sistem pendidikan dituntut menghasilkan sumber daya manusia yang memiliki kemampuan berpikir tingkat tinggi atau High Order Thinking (HOT), antara lain berpikir kritis dan kreatif (Greenstein, 2012; Larson \& Miller, 2011; The Partnership for 21st Century Skill, 2008). Kemampuan semacam itu dikenal dengan istilah 21st Century Skills.

Kemampuan abad 21 sebenarnya sudah diadaptasi oleh sistem pendidikan Indonesia yang direalisasikan dalam kurikulum 2013 (K13) yang juga mengadopsi pendekatan saintifik (Kamiludin \& Suryaman, 2017; Murti, 2015; Wahyudin, Rusman, \& Rahmawati, 2017). Penerapan pendekatan saintifik dimaksudkan agar peserta didik terbiasa dengan cara berpikir ilmuwan sehingga nantinya peserta didik akan memiliki kemampuan High Order Thinking (HOT). Namun, setelah beberapa tahun diterapkan, implementasi kurikulum 2013 belum memberikan hasil yang memuaskan, utamanya dalam bidang sains.

Kemampuan High Order Thinking (HOT) merupakan kemampuan berpikir yang lebih tinggi daripada sekedar menghafal fakta, menjelaskan fakta maupun menerapkan peraturan dan prosedur (Nugroho \& Suryadarma, 2018). Kemampuan High Order Thinking (HOT) didasari dari kemampuan siswa dalam memahami suatu konsep (Nugro ho \& Suryadarma, 2018). Maka, sudah semestinya untuk menunjang tercapainya kemampuan High Order Thinking (HOT), kemampuan pemahaman konsep juga perlu dimiliki oleh peserta didik.

Dalam pembelajaran sains termasuk juga biologi, kemampuan penting yang dijadikan tujuan adalah pemahaman konsep (Calvalcante, Newton, \& Newton, 1997; Gabel, 2003; Moran \& Keeley, 2015; Santrock, 2008). Hal ini juga relevan dengan karakteristik materi biologi yang terkemas dalam kumpulan fakta dan konsep tentang makhluk hidup dan lingkungannya (Çimer, 2012; Sudjoko, 2001). Konsep merujuk pada seperangkat makna yang berisi keteraturan, pola hubungan antara objek 
dan peristiwa (Nugroho \& Suryadarma, 2018), yang memiliki ciri dan karakteristik yang terlihat sama (Chiappetta \& Koballa, 2010; Clark \& Mayer, 2011). Konsep merupakan suatu abstraksi yang digunakan sebagai dasar dari klasifikasi serta penentuan tindakan yang akan dilakukan (Moran \& Keeley, 2015).

Pemahaman konsep merupakan kemampuan peserta didik dalam memahami dan memaknai suatu objek, peristiwa, serta hubungan antara objek dan peristiwa tersebut dengan menggunakan bahasa sendiri (Anderson, 2010; Chiappetta \& Koballa, 2010; Moran \& Keeley, 2015). Dengan memahami suatu konsep, peserta didik dapat mengaplikasikan konsep tersebut ke dalam situasi yang lebih kompleks (Mills, 2016). Dengan kata lain, dengan memahami suatu konsep, maka peserta didik dapat mengaplikasikannya dalam menyelesaikan persoalan dalam kehidupan sehari-hari. Jika peserta didik tidak memahami suatu konsep, maka dia tidak dapat memilih cara penyelesaian yang tepat jika dihadapkan pada suatu masalah (Cankoy \& Darbaz, 2010). Dalam mempelajari sains, pemahaman konsep menjadi penting dikuasai agar peserta didik dapat mengaplikasikannya dalam kehidupan nyata (Astuti \& Dasmo, 2016). Terkhusus dalam pelajaran Biologi, pemahaman konsep sangat penting karena materi yang termuat dalam pelajaran Biologi menuntut peserta didik agar dapat menyelesaikan persoalan di kehidupan nyata (Isnaini, Aini, \& Angraini, 2016).

Kemampuan pemahaman konsep merupakan kemampuan awal yang harus ada pada diri peserta didik untuk memiliki kemampuan yang lainnya (Lestari \& Surya, 2017). Dalam ranah kognitif, kemampuan pemahaman konsep merupakan kemampuan utama yang harus dimiliki peserta didik sebelum mereka mencapai ke tingkat ranah kognitif berikutnya. Kemampuan memahami harus miliki oleh peserta didik sebelum mereka mampu mengaplikasikan, menganalisis, dan mencipta (Anderson, 2010). Jadi, berdasarkan uraian di atas sudah semestinya kemampuan pemahaman konsep penting untuk diperhatikan dan dijadikan pertimbangan dalam menentukan tujuan pembelajaran.

Dalam prosesnya, pembelajaran sains seharusnya selalu memperhatikan hakikat dari sains itu sendiri. Hal ini karena beberapa penyebab gagalnya pencapaian tujuan pembelajaran adalah karena kurangnya pemahaman tentang karakteristik bidang ilmu serta hakikat bagaimana bidang ilmu tersebut diajarkan (Sudarisman, 2015). Sains, termasuk juga biologi pada hakikatnya mengandung empat unsur, yaitu proses, produk, sikap, dan aplikasi (Chiappetta \& Koballa, 2010; Siahaan \& Suryana, 2010). Proses pembelajaran berdasarkan hakikat sains adalah proses pembelajaran yang mengaktifkan peran peserta didik untuk menemukan pengetahuannya sendiri. Idealnya, mempelajari Biologi bukan menghafal, tetapi melalui tahapan dari proses ilmiah (Sudarisman, 2015). Setelah melalui serangkaian proses sains, peserta didik akan mengonstruksi konsep-konsep Biologi (Sudarisman, 2015) sehingga dapat memperkuat pemahaman peserta didik terhadap konsep Biologi.

Selain menerapkan pendekatan saintifik yang menjadi standar proses dalam kurikulum 2013, menciptakan proses sains di dalam kelas dapat dilakukan dengan mengaplikasikan model pembelajaran. Terdapat berbagai model pembelajaran yang dapat dijadikan alternatif bagi guru, salah satunya adalah prolem posing. Model problem posing sejalan dengan kurikulum 2013. Pengaplikasian model problem posing dapat mengaktifkan peran peserta didik dalam pembelajaran (Setiawan, Siswono, \& Ekawati, 2018). Problem posing dapat membantu guru dalam meningkatkan pemahaman konsep (Kar, 2016; Setiawan et al., 2018; Silver \& Cai, 2005). Problem posing merupakan model pembelajaran yang mengharuskan peserta didik untuk merumuskan pertanyaan atau soal secara mandiri (Akay \& Boz, 2013; Shoimin, 2017; Thobroni \& Mustofa, 2013). Dalam pelaksanaan model problem posing, peserta didik akan berperan aktif untuk membangun pengetahuannya sendiri (Mahendra, Slamet, \& Budiyono, 2017).

Untuk dapat memantapkan pemahaman konsep peserta didik terhadap materi Biologi, maka perlunya dilakukan penguatan-penguatan. Penguatan tersebut dapat melalui memberikan sarana bagi peserta didik untuk melaksanakan kegiatan belajar di luar jam pelajaran sekolah. Salah satu strategi yang dapat digunakan adalah metode resitasi. Implementasi metode resitasi adalah dengan memberikan tugas tertentu kepada peserta didik dengan harapan mereka melakukan kegiatan belajar (Djamarah \& Zain, 2013). Penerapan metode resitasi akan memperdalam pengetahuan peserta didik terhadap suatu materi (Roestiyah, 2001). Penerapan model problem posing dipadu metode rasitasi diharapkan dapat meningkatkan pemahaman konsep peserta didik. Penelitian ini dilakukan dengan tujuan untuk mengetahui keefektifan penggunaan model problem posing dipadu metode resitasi terhadap pemahaman konsep siswa.

\section{METODE}

Penelitian ini merupakan quasi experiment. Tujuan penelitian ini adalah untuk mengetahui keefektifan penggunaan model problem posing dipadu metode resitasi terhadap pemahaman kondep siswa. Desain penelitian yang digunakan adalah pretest posttest control group design, dengan grup eksperimen dan grup kontrol. Sampel penelitian adalah 34 orang siswa dalam grup eksperimen dan 34 orang siswa dalam grup kontrol. Penentuan sampel menggunakan teknik cluster random sampling. Grup eksperimen diberi perlakuan berupa proses belajar menggunakan model problem posing dipadu metode resitasi. Sedangkan grup kontrol menggunakan pendekatan saintifik 5M sebagai metode konvensional.

Instrumen yang digunakan dalam penelitian, meliputi perangkat ajar berupa silabus, RPP, dan instrumen tes. Instrumen tes berupa 40 butir soal pilihan ganda untuk mendapatkan data kemampuan pemahaman konsep. Perangkat ajar yang digunakan telah melalui validasi isi oleh dosen ahli (expert), sedangkan instrumen tes pemahaman konsep telah melalui validasi isi dan validasi empiris. 
Teknik analisis data meliputi uji prasyarat dan uji hipotesis dengan bantuan SPSS 24 for windows. Uji prasyarat yang diperlukan adalah uji normalitas dan uji homogenitas. Setelah uji prasyarat, hipotesis diujikan dengan menggunakan uji independent $t$-test. Selanjutnya dilakukan perhitungan nilai N-Gain untuk mengetahui keefektifan metode pembelajaran yang digunakan.

\section{HASIL}

Data dalam penelitian ini adalah nilai kemampuan pemahaman konsep siswa yang didapatkan dari tes pilihan ganda. Data pemahaman konsep diambil sebelum dan sesudah perlakuan. Rata-rata nilai pemahaman konsep dari grup eksperimen (problem posing dipadu resitasi) dan grup kontrol (saintifik 5M) terangkum pada tabel 1.

Tabel 1. Deskripsi Nilai Pemahaman Konsep

\begin{tabular}{ccccc}
\hline \multirow{2}{*}{ Deskripsi } & \multicolumn{4}{c}{ Grup } \\
\cline { 2 - 5 } & Problem Posing + Resitasi & \multicolumn{2}{c}{ Saintifik 5M } \\
\cline { 2 - 5 } & Pretest & Posttest & Pretest & Posttest \\
\hline Rata-rata & 56,18 & 80,51 & 58,16 & 71,10 \\
\hline Simpangan Baku & 6,10 & 6,96 & 6,16 & 7,54 \\
\hline Nilai Minimal & 45 & 62,5 & 42,50 & 55 \\
\hline Nilai Maksimal & 67,50 & 95 & 67,50 & 82,50 \\
\hline
\end{tabular}

Hasil penelitian memberikan rata-rata nilai yang berbeda antara grup eksperimen dan grup kontrol. Data pada tabel 1 menunjukkan rata-rata nilai posttest grup eksperimen lebih tinggi jika dibandingkan dengan rata-rata nilai posttest grup kontrol. Rata-rata nilai posttest grup eksperimen sebesar 80,51 sedangkan rata-rata nilai posttest grup kontrol sebesar 71,10. Hipotesis dalam penelitian ini diuji dengan uji independent t-test. Sebelum uji hipotesis, terlebih dahulu dilakukan uji prasyarat berupa uji normalitas dan homogenitas data. Hasil uji normalitas dan homogenitas data terangkum pada tabel 2 dan 3.

Tabel 2. Hasil Uji Normalitas Data Pemahaman Konsep

\begin{tabular}{ccccc}
\hline \multirow{2}{*}{ Intervensi } & \multicolumn{3}{c}{ Kolmogorov-Smirnov } \\
\cline { 3 - 5 } & & Statistic & Df & Sig. \\
\hline \multirow{2}{*}{ Pretest } & Grup Eksperimen & 0,117 & 34 & 0,200 \\
\cline { 2 - 5 } & Grup Kontrol & 0,142 & 34 & 0,082 \\
\hline \multirow{2}{*}{ Posttest } & Grup Eksperimen & 0,118 & 34 & 0,200 \\
\cline { 2 - 5 } & Grup Kontrol & 0,111 & 34 & 0,200 \\
\hline
\end{tabular}

Tabel 3. Hasil Uji Homogenitas Data Pemahaman Konsep

\begin{tabular}{ccccc}
\hline & Levene Statistic & df1 & df2 & Sig. \\
\hline Pretest & 0,68 & 1 & 66 & 0,795 \\
\hline Posttest & 0,273 & 1 & 66 & 0,603 \\
\hline
\end{tabular}

Data pada tabel 2 menunjukkan bahwa nilai signifikansi data pretest grup kontrol sebesar 0,082 dan nilai signifikansi data pretest grup eksperimen sebesar 0,200. Sementara itu, nilai signifikansi data posttest grup kontrol dan eksperimen masingmasing sebesar 0,200 dan 0,200. Berdasarkan hasil uji normalitas didapatkan nilai signifikansi yang lebih besar dari nilai $\alpha$ $(0,05)$, sehingga Ha diterima atau data dikatakan memiliki distribusi normal. Dalam tabel 3, diketahui nilai signifikansi data pretest dan posttest grup kontrol dan eksperimen masing-masing 0,795 dan 0,603. Berdasarkan hasil uji homogenitas, didapatkan nilai signifikansi yang lebih besar dari nilai $\alpha(0,05)$ sehingga data pretest dan posttest grup eksperimen dan kontrol adalah sama atau homogen.

Setelah syarat keparametrikan terpenuhi, maka uji hipotesis dapat dilakukan dengan uji independet t-test. Uji independent t-test dilakukan untuk melihat apakah ada perbedaan rata-rata nilai posttest grup kontrol dan eksperimen. Rangkuman uji independent t-test termuat pada tabel 4.

Tabel 4. Hasil Uji Independent t-test Data Pemahaman Konsep

\begin{tabular}{ccccc}
\hline Jenis Data & Sig. (2-tailed) & $\boldsymbol{\alpha}$ & Keputusan & Keterangan \\
\hline Posttest & 0,000 & 0,05 & Ha diterima & Ada perbedaan signifikan \\
\hline
\end{tabular}


Tabel 4 menunjukkan nilai signifikansi data posttest pemahaman konsep sebesar 0,000. Nilai signifikansi tersebut lebih kecil dari nilai $\alpha(0,05)$, yang berarti Ha diterima atau terdapat perbedaan yang signifikan antara rata-rata nilai grup kontrol dan eksperimen. Setelah diketahui terdapat perbedaan yang signifikan, selanjutnya perlu diketahui nilai N-gain untuk mengetahui keefektifan metode ajar yang digunakan.

Berdasarkan perhitungan nilai N-gain, diketahui nilai N-gain grup eksperimen sebesar 0,55 yang masuk ke dalam kategori sedang, sedangkan nilai $\mathrm{N}$-gain grup kontrol sebesar 0,30 yang masuk ke dalam kategori rendah. Data nilai N-gain menunjukkan bahwa model problem posing dipadu metode resitasi yang diterapkan pada grup eksperimen memiliki efektivitas yang lebih baik jika dibandingkan metode yang digunakan dalam grup kontrol.

\section{PEMBAHASAN}

Tujuan penelitian ini adalah untuk mengetahui keefektifan penggunaan model problem posing dipadu metode resitasi terhadap pemahaman kondep siswa. Penelitian ini melibatkan dua grup siswa yang terbagi menjadi grup eksperimen dan grup kontrol. Grup eksperimen merupakan kelompok siswa yang diberi perlakuan berupa proses pengajaran dengan model problem posing dipadu metode resitasi, sedangkan grup kontrol menggunakan pendekatan saintifik 5M. Hasil penelitian menunjukkan data nilai rata-rata grup eksperimen yang lebih tinggi dibandingkan grup kontrol, yaitu 80,51 berbanding 71,10. Berdasarkan uji hipotesis melalui uji independent t-test, diketahui bahwa terdapat perbedaan yang signifikan antara rata-rata nilai grup eksperimen dan grup kontrol yang ditunjukkan dengan nilai signifikansi $0,000 \leq \alpha(0,05)$. Untuk mengetahui keefektifan metode yang digunakan, diperlukan perhitungan nilai $\mathrm{N}$-gain. Berdasarkan hasil analisis, didapatkan nilai $\mathrm{N}$-gain grup eksperimen sebesar 0,55 dan grup kontrol sebesar 0,30. Hasil analisis tersebut menunjukkan bahwa penggunaan model problem posing dipadu metode resitasi lebih efektif untuk meningkatkan pemahaman konsep siswa.

Hasil penelitian ini sesuai dengan penelitian yang dilakukan oleh Mahendra et al. (2017) dan Ferdianto \& Ghanny (2014) bahwa penggunaan model problem posing dapat meningkatkan pemahaman konsep siswa. Penggunaan model problem posing dalam pembelajaran berpengaruh baik terhadap pemahaman konsep siswa karena dalam penerapannya, problem posing akan mengaktifkan peran serta siswa dalam pembelajaran. Dengan kata lain, siswa akan berperan aktif dalam pembelajaran sehingga proses yang dialaminya akan lebih bermakna. Proses pembelajaran yang bermakna dapat membantu tercapainya kemampuan pemahaman konsep siswa (Mills, 2016; Widiyatmoko \& Shimizu, 2018). Pembelajaran yang bermakna akan memberikan peluang yang lebih besar pada siswa untuk memahami apa yang mereka pelajari. Selain itu, problem posing adalah model pembelajaran yang mengharuskan siswa membuat soal atau masalah. Melalui pengajuan soal atau masalah secara mandiri, siswa akan lebih berpotensi untuk memahami konsep dalam pembelajaran, daripada siswa hanya menjawab soal yang diajukan oleh guru (Brown \& Walter, 2005).

Penerapan model problem posing dalam pembelajaran dilakukan dalam beberapa tahapan. Pada tahap awal, siswa akan mendapatkan materi dari penjelasan guru. Materi yang dijelaskan oleh guru tersebut dijadikan titik awal dalam pembuatan soal. Pada tahap awal ini, siswa dapat menerima pengetahuan dari guru sebagai dasar dalam pengembangan pemahamannya terkait konsep materi yang dipelajari, karena menurut (Mills, 2016), awal dari memahami suatu konsep adalah siswa harus mengenal dan mengetahui terlebih dahulu konsep-konsep tersebut. Tahap yang selanjutnya adalah tahap merumuskan soal. Sebelum merumuskan soal, siswa diberi kesempatan untuk mempelajari materi dari berbagai sumber, seperti buku paket dan LKPD yang diberikan guru. Kegiatan yang dilakukan siswa tersebut dapat menunjang mereka dalam memperoleh suatu konsep karena esensi dari proses memahami konsep materi adalah dengan mempelajari apa yang terkandung dalam materi tersebut. Setelah selesai merumuskan soal, maka siswa akan mencari penyelesaian dari soal yang dibuanya sendiri atau soal yang dibuat oleh temannya. Siswa akan membaca ulang materi untuk menjawab soal-soal tersebut. Tentu hal tersebut akan berdampak pada bertambahnya pemahaman siswa terhadap konsep materi. Pembelajaran dengan menggunakan model problem posing akan memaksimalkan peran serta peserta didik, yaitu pada saat mengobservasi dan memahami materi, membuat soal, dan mencari jawaban atas soal yang dibuat. Dalam hal ini, guru hanya bertindak sebagai fasilitator.

Dalam penelitian ini, model problem posing yang diterapkan dipadu dengan metode resitasi. Tugas yang diberikan kepada siswa adalah tugas observasi sebagai dasar siswa dalam perumusan soal. Metode resitasi juga turut berperan dalam tercapainya kemampuan pemahaman konsep siswa. Sesuai dengan hasil penelitian Murniasih \& Fayeldi (2017), penggunaan metode resitasi dalam pembelajaran dapat meningkatkan kemampuan pemahaman konsep. Dengan adanya tugas yang harus dikerjakan, siswa akan menjadi aktif tidak hanya saat jam pelajaran, tetapi juga pada saat di luar jam pelajaran. Selain itu, tugas yang dilakukan siswa akan memberikan dampak pada penguatan terhadap konsep yang mereka pahami. Ketika siswa mengerjakan tugas di luar jam pelajaran, mereka akan mengulangi kegiatan, seperti membaca materi yang dipelajari sehingga pemahaman mereka terhadap suatu konsep semakin luas dan dalam. Seperti pendapat Roestiyah (2001), bahwa pengerjaan tugas dapat memperluas, memperkaya, dan memperdalam pengetahuan siswa terhadap suatu materi ataupun konsep.

\section{SIMPULAN}

Hasil dari penelitian ini menyimpulkan bahwa terdapat perbedaan yang signifikan antara pengaruh model problem posing dipadu resitasi dan saintifik 5M terhadap pemahaman konsep siswa. Hal ini dibuktikan dengan hasil uji independent ttest, dengan nilai signifikansi $0,000 \leq 0,05$. Penggunaan model problem posing dipadu dengan metode resitasi lebih efektif 
terhadap kemampuan pemahaman konsep siswa dibandingkan dengan penggunaan metode konvensional dengan pendekatan saintifik 5M. Hal ini dibuktikan dengan nilai N-gain grup eksperimen (model problem posing dipadu metode resitasi) lebih tinggi dibandingkan nilai $\mathrm{N}$-gain grup kontrol, yaitu sebesar 0,55 berbanding 0,30 .

\section{DAFTAR RUJUKAN}

Akay, H., \& Boz, N. (2013). The Effect of Problem Posing Oriented Analyses-II Course on the Attitudes Toward Mathematics and Mathematics Self-Efficacy of Elementary Prospective Mathematics Teachers. Australian Journal of Teacher Education, 35(1), 60-75. https://doi.org/10.14221/ajte.2010v35n1.6

Anderson, L. W. (2010). Kerangka Landasan untuk Pembelajaran, Pengajaran dan Asesmen (Revisi Taksonomi Pendidikan Bloom). Yogyakarta: Pustaka Belajar.

Astuti, I. A. D., \& Dasmo. (2016). Upaya Meningkatkan Motivasi Belajar dan Pemahaman Konsep IPA Peserta Didik dengan Model Pembelajaran Problem Posing. Jurnal Riset dan Kajian Pendidikan Fisika, 3(2), 39-44. https://doi.org/10.12928/jrkpf.v3i2.5143

Brown, S. I., \& Walter, M. I. (2005). The Art of Problem Posing (3rd ed.). Mahwah, New Jersey: Lawrence Erlbaum Associates.

Calvalcante, P. S., Newton, D. P., \& Newton, L. D. (1997). The Effect of Various Kinds of Lesson On Conceptual Understanding In Science. Research In Science \& Technology Education, 15(1), 185-193. https://doi.org/://doi.org/10.1080/0263514970150205

Cankoy, O., \& Darbaz, S. (2010). Effect of a Problem Posing Based Problem Solving Instruction. H.U Journal of Education, 38(1), 11-24. http://citeseerx.ist.psu.edu/viewdoc/download?doi=10.1.1.457.4670\&rep=rep1\&type=pdf

Chiappetta, E. L., \& Koballa, T. R. (2010). Science Instruction In the Middle and Secondary Schools (7th ed.). New York: Macmillan Pub. Co.

Çimer, A. (2012). What Makes Biology Learning Difficult and Effective: Students Views. Educational Research and Reviews, 7(3), 61-71. https://doi.org/10.5897/err11.205

Clark, R., \& Mayer, R. E. (2011). E-Learning and the Science of Instruction. Amerika: Pfeiffer.

Djamarah, S. B., \& Zain, A. (2013). Strategi Belajara Mengajar. Jakarta: PT. Rineka Cipta.

Ferdianto, F., \& Ghanny. (2014). Meningkatkan Kemampuan Pemahaman Matematis Siswa melalui Problem Posing. Jurnal Euclid, 1(1), 47-54. https://doi.org/10.33603/e.v1i1.343

Gabel, D. (2003). Enhancing the Conceptual Understanding of Science. Educational Horizons, 81(2), 70-76. Retrieved from https://www.jstor.org/stable/42925990?seq=1\#metadata_info_tab_contents

Greenstein, L. (2012). Assesing Skill 21st Century. A Guide to Evaluating Mastery and Authentic Learning. U.S.A: Crowin A SAGE Company.

ICASE. (2008). Promoting Scientific and Technological Literacy (STL) for All (2th ed.) (2nd ed.). Penang: Seameo Rescam.

Inanna. (2018). Peran Pendidikan dam Membangun Karakter Bangsa yang Bermoral. Jurnal Ekonomi dan Pendidikan, 1(1), 27-33. https://doi.org/https://doi.org/10.26858/jekpend.v1i1.5057

Isnaini, M., Aini, K., \& Angraini, R. (2016). Pengaruh Strategi Pembelajaran Mind Map terhadap Pemahaman Konsep pada Materi Sistem Ekskresi Kelas XI IPA SMA Negeri 1 Pampangan Oki. Jurnal Bioilmi, 2(2), 142-150. http://jurnal.radenfatah.ac.id/index.php/bioilmi/article/view/1138/956

Kamiludin, K., \& Suryaman, M. (2017). Problematika pada Pelaksanaan Penilaian Pembelajaran Kurikulum 2013. Jurnal Prima Edukasia, 5(1), 58-67. https://doi.org/10.21831/jpe.v5i1.8391

Kar, T. (2016). Prospective Middle School Mathematics Teachers' Knowledge of Linear Graphs In Context of Problem-Posing. International Electronic Journal of Elementary Education, 8(4), 643-658.

Kurnia, R. P., \& Suryadarma, I. G. P. (2016). Perangkat Pembelajaran Biologi Kegiatan Ecotourism untuk Mengasah Keterampilan Proses Sains dan Sikap Peduli Lingkungan. Jurnal Inovasi Pendidikan IPA, 2(2), 230-240. https://doi.org/http://dx.doi.org/10.21831/jipi.v2i2.12252

Larson, L. C., \& Miller, T. N. (2011). 21st Century Skills: Prepare Student for The Future. Kappa Delta Pi Record, 47(3), 121123. https://doi.org/https://doi.org/10.1080/00228958.2011.10516575

Lestari, L., \& Surya, E. (2017). The Effectiveness of Realistic Mathematics Education Approach on Ability of Students' Mathematical Concept Understanding. International Journal of Sciences: Basic and Applied Research, 34(1), 91-100.

Mahendra, R., Slamet, I., \& Budiyono. (2017). The Effect of Problem Posing and Problem Solving with Realistic Mathematics Education Approach to The Conceptual Understanding and Adaptive Reasoning. AIP Conference Proceedings, 1913(020025), 1-4. https://doi.org/10.1063/1.5016659

Mills, S. (2016). Conceptual Understanding : A Concept Analysis. The Qualitative Report, 21(3), 546-557. http://nsuworks.nova.edu/tqr/vol21/iss3/8/

Moran, R. K., \& Keeley, P. (2015). Teaching for Conceptual Understanding Inscience. Arlington: NSTA Press.

Murniasih, T. R., \& Fayeldi, T. (2017). Metode Resitasi untuk Meningkatkan Pemahaman Konsep pada Matakuliah DasarDasar Pemrograman Komputer. Jurnal Edukasi, 4(1), 8-12. https://doi.org/10.19184/jukasi.v4i1.5083

Murti, K. E. (2015). Pendidikan Abad 21 dan Aplikasinya Dalam Pembelajaran di SMK. http://www.p4tksbjogja.com/images/artikel/Pendidikan_Abad_21_dan_Aplikasinya_dalam_Pembelajaran_di_SMK_-_Kuntari.pdf 
Nugroho, R. A., \& Suryadarma, I. G. P. (2018). Pengaruh Servant Leadership Learning dengan Concept Mapping terhadap Pemahaman Konsep dan Berpikir Kritis Siswa. Jurnal Inovasi Pendidikan IPA, 4(1), 114-127. https://doi.org/http://dx.doi.org/10.21831/jipi.v4i1.9823

Roestiyah. (2001). Strategi Belajar Mengajar. Jakarta: PT. Rineka Cipta.

Rustaman, N. Y. (2011). Pendidikan dan Penelitian Sains dalam Mengembangkan Keterampilan Berpikir Tingkat Tinggi untuk Pembangunan Karakter. Makalah Seminar Nasional VIII Pendidikan Biologi, FKIP UNS, Surakarta, 8(1), 15-34. https://jurnal.uns.ac.id/prosbi/article/viewFile/7248/6428

Sadiqin, I. K., Santoso, U. T., \& Sholahuddin, A. (2017). Pemahaman Konsep IPA Siswa SMP melalui Pembelajaran Problem Solving pada Topik Perubahan Benda-benda di Sekitar Kita. Jurnal Inovasi Pendidikan IPA, 3(1), 52-62. https://doi.org/10.21831/jipi.v3i1.12554

Santrock, J. W. (2008). Psikologi Pendidikan. Jakarta: Prenada Media Grup.

Setiawan, E. P. A., Siswono, T. Y. E., \& Ekawati, R. (2018). Implementation of Problem Posing Learning on Conceptual Understanding and Adaptive Reasoning. Social Science, Education and Humanities Research, 212(1), 485-488. https://doi.org/10.2991/icei-18.2018.104

Shoimin, A. (2017). 68 Model Pembelajaran Inovatif dalam Kurikulum 2013. Yogyakarta: Ar-Ruzz Media.

Siahaan, P., \& Suryana, I. (2010). Hakekat Sains dan Pembelajaran Sains. 1-17. http://file.upi.edu/Direktori/fpmipa/jur._pend._fisika/195803011980021-parsaoran_siahaan/MakalahModul/Pelatihan_Guru_MIPA_Papua_Barat-11-15_Januari_2010/hakikat_sains_dan_Pembelajaran_IPAx.pdf

Silver, E., \& Cai, J. (2005). Assessing Students' Mathematical Problem Posing. Teaching Children Mathematics, 12(1), 129135.

Sudarisman, S. (2015). Memahami Hakikat dan Karakteristik Pembelajaran Biologi dalam Upaya Menjawab Tantangan Abad 21 serta Optimalisasi Implementasi Kurikulum 2013. Florea : Jurnal Biologi dan Pembelajarannya, 2(1), 29-35. https://doi.org/10.25273/florea.v2i1.403

SThobroni, M., \& Mustofa, A. (2013). Belajar dan Pembelajaran: Pengembangan Wacana dan Praktik Pembelajaran dalam Pembangunan Nasional. Yogyakarta: Ar-Ruzz Media.

Wahyudin, D., Rusman, \& Rahmawati, Y. (2017). Penguatan Life Skills dalam Implementasi Kurikulum 2013 pada SMA (Sekolah Mengenah Atas) di Jawa Barat. Mimbar Pendidikan: Jurnal Indonesia untuk Pendidikan, 2(1), 65-80. https://doi.org/http://dx.doi.org/10.17509/mimbardik.v2i1.6023

Widiyatmoko, A., \& Shimizu, K. (2018). An Overview of Conceptual Understanding In Science Education Curriculum in Indonesia. Journal of Physics: Conference Series, 983(012044), 1-6. https://doi.org/10.1088/1742-6596/983/1/012044 